\title{
Complexity of Differentiating Cerebral-Renal Salt Wasting from SIADH, Emerging Importance of Determining Fractional Urate Excretion
}

\author{
John K. Maesaka, Louis Imbriano, \\ Shayan Shirazian and Nobuyuki Miyawaki \\ Department of Medicine, Winthrop-University Hospital, Mineola, NY, \\ SUNY Medical School, Stony Brook, NY,
}

USA

\section{Introduction}

The current approach to the diagnosis and treatment of hyponatremia is in a state of flux, largely because of an unresolved controversy regarding the relative prevalence of the syndrome of inappropriate secretion of antidiuretic hormone (SIADH) and cerebral salt wasting, or preferably renal salt wasting (RSW). The recent awareness that symptoms are now being attributed to even mild hyponatremia has led to recommendations to treat virtually all hyponatremics. (Arief et al, 1976; Berl et al, 2010; Decaux, 2006, 2009; Gankam Kegne et al, 2008; Hoorn et al, 2009; Renneboog et al, 2006; Sterns et al,2009; Schrier, 2010) This tendency to treat even mild hyponatremia introduces an urgency to resolve the diagnostic dilemma of differentiating two syndromes, SIADH and RSW, with divergent therapeutic goals, to water-restrict in SIADH or administer salt and water in RSW. We propose to define RSW by supporting data and review the pathophysiology of RSW, the derivation and evolution of the controversy over the relative prevalence of SIADH and RSW, and methods to differentiate SIADH from RSW. We will also review the emerging value of determining fractional excretion (FE) of urate in the evaluation of patients with hyponatremia by emphasizing our recent observations in reset osmostat, identify conditions that predispose to RSW, amplify the possibility that RSW might exist in patients with an increased FEurate without hyponatremia and propose an algorithm where FEurate is central to the evaluation of hyponatremia. We will also advocate and hopefully justify changing the designation, cerebral salt wasting, to renal salt wasting, and briefly discuss different strategies to treat hyponatremia.

\section{Definition of RSW}

In our view, RSW is most accurately defined as, "extracellular volume (ECV) depletion due to a renal sodium transport abnormality with or without high urinary sodium concentration (UNa), presence of hyponatremia or cerebral disease and normal renal, adrenal and thyroid function". (Maesaka et al, 2009) We will provide data to support our contention that UNa can be low in RSW, and how RSW can occur in normonatremic patients and in patients 
without cerebral disease. Although an increased FEurate has been demonstrated in a number of patients with RSW, we will withhold including FEurate to our definition of RSW until there are more confirmatory data.

\subsection{Pathophysiology of RSW}

RSW starts with a disease entity that appears to induce production of a natriuretic factor(s) that inhibits mainly proximal tubule sodium transport and possibly other solutes such as urate. Depending on the balance between the severity of the sodium transport defect and sodium intake, ECV depletion of varying magnitude ensues. The patient will first enter a stage of negative sodium balance, which will stimulate the renin-angiotensin aldosterone system, reduce atrial/brain natriuretic peptide (A/BNP), alter glomerular hemodynamics and possibly activate neural factors that attempt to decrease sodium excretion. (Abuelo, 2007) In some, a combination of inadequate sodium intake and profound inhibition of tubule sodium transport can lead to severe, symptomatic ECV depletion that is manifested as postural hypotension, unsteady gait, and postural somnolence, dizziness and slurred speech. (Gutierrez et al, 2007; Maesaka et al, 1990, 2007; Wijdicks et al, 1985) A more common scenario is a milder defect in sodium transport and mild ECV depletion that cannot be appreciated unless we refine our ability to diagnose RSW accurately. There are, therefore, different degrees of volume depletion that depend on the severity of the inhibition of renal sodium transport and salt and water intake. The true prevalence of RSW, therefore, cannot be appreciated until we refine methods of determining ECV accurately by simple methods or develop other as yet unidentified methods of defining RSW. Moreover, because SIADH and RSW typically present with hyponatremia, high urine osmolality and $\mathrm{UNa}$, these overlapping features of RSW and SIADH and divergent therapeutic goals of each syndrome introduce an urgency to differentiate one syndrome from the other to achieve these opposing therapeutic goals.

The volume-depleted subject must reach an equilibrated state of sodium balance, otherwise a sustained negative sodium balance will result in total loss of body sodium and collapse of the vascular system. Sodium excretion and UNa can thus be low, if sodium intake is low. (Maesaka et al, 2007) A similar sequence of negative sodium balance followed by equilibration has been noted for SIADH. (Jaenike et al, 1961) The increase in water reabsorption maintains ECV at high normal and increases ANP levels, which can cause natriuresis by multiple factors. (de Zeeuw et al, 1992)

Interestingly, plasma renin in RSW can be variable depending on sodium intake, whereas plasma aldosterone tends to be increased irrespective of sodium intake when volume depleted. (Bitew et al, 2009; Maesaka et al, 2007) In this scenario, we noted increased plasma renin in a patient with RSW while on a low sodium intake. The decrease in sodium delivery to the distal tubule stimulated COX2 activity and increased plasma renin. (Traynor et al, 1999) On the other hand, a salt wasting patient on a normal sodium intake had higher sodium delivery to the distal tubule by virtue of an underlying decrease in proximal tubule sodium transport that failed to increase COX2 activity and maintained normal plasma renin, while being volume depleted. (Bitew et al, 2009; Traynor et al, 1999)

In contrast to $\mathrm{SIADH}$, when $\mathrm{ADH}$ production fails to respond to conventional volume and osmolar stimuli, there is appropriate stimulation of ADH production in RSW by ECV depletion. The volume stimulus for ADH production is more potent than the osmolar effect 
on $\mathrm{ADH}$ production, so a volume depleted patient continues to increase $\mathrm{ADH}$ production, increase free water reabsorption and decrease serum sodium and osmolality. (Robertson \& Ganguly, 1986) Administration of saline in our patient with RSW eliminated the volume stimulus for $\mathrm{ADH}$ production to allow the coexisting hypoosmolality of plasma to inhibit $\mathrm{ADH}$ production to indeterminate levels, thus decreasing urine osmolality, increase free water excretion and increase serum sodium, figure 1.



Fig. 1. Urine osmolality and serum sodium concentration during saline infusion at 125 $\mathrm{ml} / \mathrm{hr}$. over 48 hour period. Note dilution of urine 13 hours after initiation of saline, at which time a previously increased plasma $\mathrm{ADH}$ was not detectable, appropriate AD secretion. See text. (reproduced with permission from publisher)

This appropriate increase in plasma ADH in a patient with unequivocal RSW illustrates this important physiologic difference between RSW and SIADH. (Maesaka et al, 2007, 2009) As noted earlier, the task of clinically determining whether the increase in plasma ADH levels are appropriate or inappropriate rests solely on differences in ECV, since both present with hyponatremia, high urine osmolality and UNa. Our reliance on the assessment of ECV becomes critical in differentiating SIADH from RSW. Our inability to assess this critical parameter remains central to the unresolved controversy regarding the prevalence of SIADH and RSW. (Maesaka et al, 2009, 1999; Oh \& Carroll, 1999; Singh et al, 2002).

\subsection{Natriuretic factor(s) in RSW}

Atrial or brain natriuretic peptide (A/BNP) has been frequently mentioned as a possible cause of the salt wasting in RSW. (Ellison \& Berl, 2007; Palmer, 2003) A/BNP has been reported to be increased in patients with subarachnoid hemorrhage (SAH), a condition that has been shown to have a high prevalence for RSW, but it has also been reported to be increased in a non salt wasting syndrome such as SIADH and salt-retaining conditions such as congestive heart failure. (Burnett et al, 1986; Fichman et al, 1974; Wijdicks et al, 1991) The low normal ANP level in RSW is consistent with the volume-depleted state and strongly argues against any role of ANP in salt wasting. (Maesaka et al, 2007, Vogel, 1963) 
ANP increases GFR, decreases renal blood flow and blood pressure and increases sodium excretion by the increase in GFR and inhibition of sodium transport in the proximal and distal tubule. ANP responds to changes in intravascular volume and would be lower in volume depleted states such as RSW. (Maesaka et al, 2007) The contribution of ANP in maintaining sodium homeostasis has not been clearly established, being considered by some to have no role as compared to others who feel ANP does contribute to sodium balance. (de Zeeuw et al, 1992).

The infusion of BNP into normal subjects increased GFR, decreased renal plasma flow, increased urine flow and sodium excretion, and inhibited plasma renin without affecting blood pressure, angiotensin II or aldosterone levels. There was evidence for inhibition of proximal tubule and larger inhibition of distal sodium transport. (Jensen, 1998) There is questionable relevance of these findings to RSW because A/BNP responds to changes in intravascular volume and are, thus, lower in RSW. (Maesaka et al, 2007; Vogel, 1963) We favor a natriuretic factor that does not have characteristics of A/BNP that is evident in plasma and urine of patients with evidence for RSW, see below.

We infused plasma from patients with neurosurgical and Alzheimer's diseases (AD) with increased FEurate and normonatremia into rats, and demonstrated a significant increase in FElithium and FENa, suggesting that a natriuretic factor(s) had a predominant effect on proximal tubule sodium transport. (Maesaka et al, 1993, 1993) Blood pressure and GFR remained unchanged from baseline and from controls throughout the study. Since lithium transport follows sodium transport on a one to one basis in the proximal tubule in the absence of nonelectrolyte solutes such as mannitol, the significant increase in FElithium from 22.3 and $27.2 \%$ in control animals to 36.6 and $41.7 \%$ in neurosurgical and AD patients, respectively, indicates that the same fraction of filtered sodium escaped reabsorption in the proximal tubule. (Dorhout Mees,1990; Leyssac et al, 1990; Maesaka et al 1993, 1993) This increase in distal delivery of sodium only increased FENa significantly from control values of 0.3 and $0.33 \%$ to 0.59 and $0.63 \%$ in rats infused with plasma of neurosurgical and AD, respectively, indicating that the distal tubule had actually increased distal sodium reabsorption from control values of 22.0 and $26.87 \%$ to 36.01 and $41.07 \%$ of the filtered sodium. (Maesaka et al, 1993, 1993) The significant increase in FENa indicated a net sodium loss in animals infused with plasma of neurosurgical and AD. An unresolved question is whether the increase in the distal delivery of sodium exceeded the capacity of the distal tubule to transport sodium or whether the natriuretic factor(s) had an effect on distal sodium transport as well. These data, nevertheless, indicate that the major site of natriuretic activity resides in the proximal tubule and there was a net loss of sodium. In RSW the increase in FEurate, an anion that is exclusively transported in the proximal tubule, supports our proposal that the major site of solute transport abnormality in RSW is in the proximal tubule and introduces the possibility that the natriuretic factor(s) might affect more than one transporter. (Maesaka \& Fishbane, 1998) Moreover, these data do not have any similarities to the effects of A/BNP.

More recently, ammonium precipitates of urinary proteins of 5 of 6 neurosurgical patients with increased FEurate and normonatremia inhibited transcellular ${ }^{22} \mathrm{Na}$ transport in a dosedependent manner across cultured pig proximal tubule cells, LLC-PK1, in transwells, as compared to precipitates from urine of neurosurgical patients with normal FEurate and normonatremia, and SIADH. (Youmans \& Maesaka, 2011) These data support our previous 
studies in neurosurgical and $\mathrm{AD}$, who had increased FEurate with normonatremia, an association that is highly suggestive of RSW. This conclusion is consistent with the frequency with which RSW is seen in neurosurgical diseases, with and without hyponatremia, see below. (Nelson et al, 1981; Sivakumar et al, 1994; Singh et al, 2002; Wijdicks et al, 1985)

\section{Controversy over the relative prevalence of RSW and SIADH}

The consistent view among internists and nephrologists is that RSW is a rare entity as compared to neurosurgeons, who consider RSW to be a common disorder. This important controversy exists because of the difficulty with which one syndrome can be differentiated from the other by usual clinical criteria. Because of overlapping clinical parameters such as hyponatremia, concentrated urines with high $\mathrm{UNa}$, hypouricemia, increased FEurate, associations with intracranial diseases and normal renal, thyroid and adrenal function, there is a diagnostic dilemma that must be resolved in order to arrive at an appropriate therapeutic strategy for both syndromes. The only difference on first exposure with the patient is the volume depletion in RSW and increased volume in SIADH. (Bitew et al, 2009; Schwartz et al, 1957) Unfortunately, the clinical assessment of the volume status of nonedematous patients has been regarded as consistently inaccurate by usual clinical criteria. (Chung et al, 1987; Maesaka et al, 1999; Oh \& Carroll; 1999; Singh et al, 2002)

We and others have encountered patients with RSW, who became symptomatic while being water-restricted for an erroneous diagnosis of SIADH. (Gutierrez et al ,2007; Maesaka et al, 1990,2007; Wijdicks et al, 1985 ) The common teaching that RSW is a rare clinical entity virtually eliminates its consideration when encountering patients with nonedematous hyponatremia. Because the major diagnostic conundrum rests with the volume status of these patients, we will review volume studies, mainly in neurosurgical patients, and offer strategies by which we can differentiate one syndrome from the other. In our view, the myriad of studies that have been published on cerebral/renal salt wasting, including the original report on cerebral salt wasting, has not adequately supported the diagnosis of RSW and have contributed to misconceptions. We will attempt to identify parameters by which the diagnosis of RSW can be made in order of their priority. We hope this review will provide information that will allow the reader to assess critically the merit of manuscripts on RSW and SIADH.

\section{Evolution of the controversy over the existence and prevalence of RSW}

The derivation of the controversy regarding the existence and relative prevalence of RSW and SIADH can be appreciated by a brief review of salt balance in normal subjects. Studies in Yanomamo Indians, the "no salt society", support the notion that we require virtually no salt in our diet to maintain normal ECV. (Hollenberg, 1980; Oliver et al, 1975) In Yanomamo Indians, the mean sodium excretion is $1 \mathrm{mmol} /$ day, mean serum sodium $140 \mathrm{mmol} / \mathrm{L}$, mean urine volume $1 \mathrm{~L} /$ day and mean blood pressure 102/62 $\mathrm{mmHg}$. (Oliver et al, 1975) These studies suggest that we require little or no salt in our diets to maintain normal ECV.

Normal kidneys appear to have an innate sense of what is a normal ECV for that individual and adjust to any fluctuations in sodium intake to maintain ECV within narrow limits. (Hollenberg, 1980) The adjustments, however, are not instantaneous as sodium excretion will exceed input for up to 5 days before reaching equilibrium after an acute reduction in 
sodium intake. (Valtin, 1997) When a normal subject is placed in negative sodium balance by increasing urinary sodium excretion by diuretics or increased sweating, urinary sodium excretion decreases to as low as $1 \mathrm{mmol} /$ day. (McCance, 1936; Strauss et al, 1958) Sodium excretion does not increase until the sodium losses have been replenished. (McCance, 1936; Strauss et al, 1958) This important role of normal kidneys to conserve sodium, when in a state of negative sodium balance is, in retrospect, the basis for the birth of the term cerebral salt wasting syndrome in 1950. (Peters et al, 1950) Peters et al reported 3 subjects with cerebral disease, acute encephalitis, subarachnoid hemorrhage and bulbar poliomyelitis. They concluded unconvincingly that these patients presented evidence of salt wasting, which was characterized by nitrogen retention, low blood pressure and correction of their hyponatremia by large salt intake. Nitrogen retention occurs in a volume depleted patient, referred to as prerenal azotemia, with retention of urea or nonprotein nitrogen (NPN), approximately double the BUN. (Abuelo, 2007) This is a reasonable assumption because urea excretion increases with any increase in urine output, even in RSW during volume repletion. (Shannon, 1936) NPN decreased from a baseline 44 to $25 \mathrm{mg} / \mathrm{dL}$ after receiving large amounts of salt in the first case. Only one NPN determination was reported in the second case with $\mathrm{SAH}$ and none was reported in the third case with bulbar poliomyelitis. The blood pressure in the first patient was $110 / 70 \mathrm{mmHg}$ when the NPN was $44 \mathrm{mg} / \mathrm{dL}$ with preceding blood pressures of $120 / 80$ to $130 / 88 \mathrm{mmHg}$ without testing for postural changes in blood pressure or pulse. The second patient with SAH had one blood pressure reading of 220/110 $\mathrm{mmHg}$ and none was reported for the third case. The hyponatremia in all 3 patients did not respond to long periods of increased salt intake. The salt balance study that lasted 39 hours revealed the patient to be in negative sodium balance after salt intake was acutely reduced from $15 \mathrm{~g} /$ day to no salt intake. This delay in reaching equilibrium on the third day after an acute reduction in salt intake was construed as salt wasting, but is actually consistent with observations made in normal subjects. (Valtin, 1997) The negative sodium balance for 39 hours after an acute reduction in sodium intake does not justify the diagnosis of salt wasting. The first "dehydrated"case, however, could have had salt wasting. McCance and Strauss et al reported that a volume depleted subjects would avidly conserve sodium until their sodium losses were replaced. (McCance, 1936; Strauss et al, 1958) This "dehydrated" or assumed volume depleted patient had a urine chloride of $61.6 \mathrm{mmol} / \mathrm{L}$, which can be explained by RSW. The inability to assess clinically the state of ECV has been the basis for doubting the existence of RSW. The same shortcomings were repeated in another report by the same authors on salt wasting. (Welt et al, 1952)

Four years later, Cort reported a hyponatremic patient with astrocytoma and papilledema, who had signs of dehydration. (Cort, 1954) Sodium intake of $15 \mathrm{~g} /$ day for many days failed to correct the hyponatremia. In a nine-day balance study, sodium intake was acutely reduced to $142.5 \mathrm{mg} /$ day. The patient received corticotrophin on days 4,5 and 6 , deoxycorone on days 7,8 and 9 and restarted on $15 \mathrm{mg} /$ day salt on day 10. The patient went into negative sodium balance of $100 \mathrm{mmol}$ on the first day and $60-70 \mathrm{mmol} /$ day for the next 8 days. Sodium balance was unaffected by corticotrophin or deoxycortone. This study was compared to a similar study by McCance, who found normal subjects to go into sodium balance by the $5^{\text {th }}$ day. (Cort, 1954) Determinations of daily chloride space revealed a $1.4 \mathrm{~L}$ reduction on the first day and $690 \mathrm{ml}$ on the $9^{\text {th }}$ day. Resumption of $15 \mathrm{~g} /$ day salt intake increased the chloride space by $1 \mathrm{~L}$ and her serum sodium "restored toward normal". (Cort, 1954) The reduction in chloride space and prolonged negative sodium balance prove the existence of RSW. 
In 1957 Schwartz et al published their seminal report on SIADH that captured the fancy of physiologists and clinicians by reproducing the data in studies of vasopressin injections in healthy subjects by Leaf et al to propose the inappropriate secretion of $\mathrm{ADH}$ without the benefit of measuring plasma ADH levels. (Leaf et al, 1953; Schwartz et al, 1957) They proved convincingly that a hyponatremic patient, who presents with a concentrated urine, high $\mathrm{UNa}$ and increased ECV, as determined by radiosulfate measurements of $\mathrm{ECV}$, must be due to an inappropriate secretion of $\mathrm{ADH}$. ADH did not respond to the usual volume or osmolar stimuli and thus termed it inappropriate. The hyponatremia that was associated with a high $\mathrm{UNa}$ of $70 \mathrm{mmol} / \mathrm{L}$ and euvolemia or hypervolemia strengthened by determination of radiosulfate space, defined a syndrome that was not consistent with cerebral or renal salt wasting. (Schwartz et al, 1957)

There are several characteristics of SIADH that are worth reviewing as they relate to hyponatremia. These patients go into a period of negative sodium balance followed by an equilibrated state when sodium intake matches output. (Janenike \& Waterhouse,1961) There is an increased blood volume as determined by sulfate space and by radioiodinated serum albumin and ${ }^{51} \mathrm{Cr}$ labeled red blood cells. (Bitew et al, 2009; Schwartz et al, 1957) The hypervolemia reduces plasma renin and aldosterone and increase plasma A/BNP. (Bitew et al, 2009; Fichman et al, 1974) GFR increases and urine osmolality is invariably concentrated. (Beck, 1979) Urine osmolality can, however, be dilute under circumstances of "ADH escape". Dilute urines have been noted after rapid infusion of saline at $2 \mathrm{~L}$ over a $2 \mathrm{hr}$ period and after reducing sodium intake. (Jaenike \& Waterhouse, 1961; Schwartz et al, 1957) Several possible explanations for this interesting phenomenon include a down regulation of $\mathrm{V}_{2}$ receptor or increased urine flow rates cannot equilibrate with the hypertonic medulla. (Hoorn et al, 2005)

An unappreciated observation is an increase in serum sodium despite high fluid intake in SIADH. A balance study reported an increase in serum sodium from 105 to $135 \mathrm{mmol} / \mathrm{L}$ over an 8 day period, when the mean fluid intake was $2648 \mathrm{ml}$ /day and mean daily sodium intake of $315 \mathrm{mmol} /$ day. The mean sodium concentration of $124.4 \mathrm{mmol} / \mathrm{L}$ in the input fluid was higher than the mean UNa of $86.8 \mathrm{mmol} / 1$ over the 8 day period. The sodium concentration in the intake fluid exceeded UNa on every day of the study, suggesting that serum sodium can increase even in SIADH as long as sodium concentration in the intake fluid exceeds UNa, regardless of the intake volume. (Schwartz et al, 1957) This reasoning can be applied to desalination when saline infusion decreases serum sodium. (Steele et al,1997). In the first case of SIADH, serum sodium decreased from 121 to $114 \mathrm{mmol} / \mathrm{L}$ after saline infusion when UNa was $70 \mathrm{mmol} / \mathrm{L}$ and to $103 \mathrm{mmol} / \mathrm{L}$ after hypertonic saline before undergoing a metabolic study. It is unlikely that serum sodium decreased while receiving saline, with a sodium concentration of $155 \mathrm{mmol} / \mathrm{L}$, when $\mathrm{UNa}$ was $70 \mathrm{mmol} / \mathrm{L}$. This is not consistent with desalination. (Steele et al, 1997) The best explanation for this phenomenon is an unrecorded intake of water that decreased the input sodium concentration below UNa. (Schwartz et al, 1957)

These elegantly designed studies in the initial report of SIADH proved that a hyponatremic patient can have high UNa without invoking RSW, largely because the volume status was shown to be increased by credible methods of determining ECV and not by tenuous clinical criteria as in the original report. (Peters et al, 1950) The existence of cerebral salt wasting was appropriately questioned. Since the assessment of ECV is critical in differentiating SIADH from RSW, it would be appropriate to review the various methods by which we assess ECV. 


\section{Assessment of extracellular volume}

It is generally agreed that the assessment of ECV by clinical criteria is fraught with inaccuracies that the term "appeared dehydrated" is not acceptable for clinical and research purposes. (Chung et al, 1987; Maesaka et al, 1999; Oh \& Carroll, 1999; Singh et al, 2002) The usual criteria of tissue turgor, axillary sweat, dry mucus membranes, neck vein distention or even postural hypotension in a nonedematous patient have been collectively inaccurate in assessing ECV. Even the presence of postural hypotension must consider autonomic dysfunction as we reported in a hyponatremic patient with autonomic failure and SIADH, proven by increased blood volume by gold standard radioisotope-dilution methods and depressed plasma renin and aldosterone. (Bitew et al, 2009) The use of plasma renin and aldosterone to differentiate SIADH from RSW can be helpful under ideal circumstances. In SIADH, plasma renin and aldosterone levels should be depressed, reflecting a slightly hypervolemic state, while in RSW, both levels should be increased, reflecting volume depletion. Clinically, however, determinations of plasma renin and aldosterone are delayed. Their diagnostic value is limited by a variety of exogenous factors. They include medication like ACE inhibitors, ARBs, B-Blockers, NSAIDS, heparin, diuretics and hyperuricemia. (Mulatero et al, 2002; Eraranta et al, 2008) A/BNP has not been used to differentiate SIADH from RSW.

It appears that noninvasive methods to assess ECV have limited value. Invasive methods have also been limited by various factors. A commonly used parameter is to measure central venous pressures $(\mathrm{CVP})$. CVP has a poor correlation with concomitant radioisotope dilution measurements of blood volume and is also being discarded as a guide to fluid management. (Marik et al, 2008) The use of bioimpedance to determine volume in different compartments of the body is not useful as a single determination. (Schneditz, 2006)) Pulmonary wedge pressures are limited by a failure consistently to predict ECV but also by their invasiveness. (Godje et al, 1998)

There are two credible methods that can reliably determine ECV with greater accuracy than methods discussed above. One is the gold standard radioisotope-dilution method, using radioiodinated serum albumin and/or ${ }^{51} \mathrm{Cr}$-tagged red blood cells, and the other, determination of total body water by deuterium and extracellular water by sodium bromide. As will be discussed below, there are a limited number of studies using radioisotope-dilution methods in SIADH and RSW and none using measurements of total and extracellular water in either of these two groups of patients.

\subsection{Volume studies using radioisotope-dilution and other pertinent methodologies}

As reviewed above, estimates of ECV have been made by determining chloride and thiosulfate spaces to support other criteria to establish the diagnosis of RSW and SIADH, respectively. (Cort, 1954; Schwartz et al, 1957) The gold standard for determining blood volume is by radioisotope dilution methods including radioiodinated serum albumin and/or ${ }^{51} \mathrm{Cr}$ labeled red blood cells. A study of 12 neurosurgical hyponatremic patients with UNa ranging from $41-203 \mathrm{mmol} / \mathrm{L}$ had blood volume determined by ${ }^{51} \mathrm{Cr}$ tagged red cells and radioiodinated serum albumin. Ten of the 12 patients had decreased blood volume and 2 had increased blood volume as compared to 6 control patients. (Nelson et al, 1981) The high UNa of 41 to $203 \mathrm{mmol} / \mathrm{L}$ suggests that $83.3 \%$ had RSW and 16.7\% had SIADH. Eight patients had subarachnoid hemorrhage (SAH). In another study, plasma volume was 
determined by radioiodinated serum albumin in 21 patients on the first day of admission within 48 hours after SAH and on the $6^{\text {th }}$ day after SAH. Comparisons between the first and second volume determination revealed blood volume to decrease in 8 of 9 hyponatremic patients, suggesting that $88.9 \%$ had RSW and $11.1 \%$ had SIADH. UNa values were not reported. (Wijdicks et al, 1985) Interestingly, plasma volume was decreased in 8, 66.7\%, and increased in 4, 33.3\%, of 12 nonhyponatremic patients with SAH, suggesting that RSW can occur in nonhyponatremic patients. Moreover, all 8 hyponatremic and 8 of 12 nonhyponatremic patients with decreased blood volume were in negative sodium balance. The increased blood volume in the 4 patients with normonatremia raises the question of whether or not SIADH can occur with normonatremia. In a separate study, Water restriction in volume depleted patients with SAH increased morbidity and mortality, probably due to decreased perfusion of brain and extension of ischemia in an already compromised circulation. (Wijdicks et al, 1985)

Another study used ${ }^{51} \mathrm{Cr}$ tagged red cells and CVP measurements in 18 hyponatremic patients of various etiologies with UNa of 43-210 mmol/L. (Sivakumar et al, 1994) Seventeen of 18 patients had decreased blood volumes, 18 of 18 patients had decreased CVP and all 18 patients corrected their hyponatremia within 72 hours after initiating saline infusion. The high UNa, decreased blood volume and correction of hyponatremia within 72 hours after initiating saline therapy argue strongly for RSW. We demonstrated a similar correction of hyponatremia within 48 hours after initiation of saline therapy in two patients with RSW and failure of saline therapy to correct the hyponatremia in two patients with SIADH. (Bitew et al, 2009; Maesaka et al, 2007) The three neurosurgical studies demonstrate by acceptable methods of determining ECV, that RSW is much more common than SIADH in neurosurgical patients, especially $\mathrm{SAH}$.

A study in neurosurgical patients determined blood volume by ${ }^{51} \mathrm{Cr}$ labeled red cells in 20 hyponatremic and 20 nonhyponatremic "control" patients. Patients with evidence of "dehydration or hypovolemia" were excluded. All met criteria for SIADH. (Brimioulle et al, 2008) The exclusion of dehydrated or hypovolemic patients might have excluded patients with RSW and meeting the criteria for SIADH would include patients with RSW. Blood volumes were found to be comparable in the "control" and hyponatremic groups, suggesting that the hyponatremic group was entirely SIADH. Interestingly both the "control" and experimental groups were hypouricemic, mean serum urate 2.7 and 1.3 $\mathrm{mg} / \mathrm{dL}$ and had high mean FEurate of $19 \%$ and $32 \%$ (normal 5-10\%), respectively. There is ample evidence to suggest that the high FEurate in the hyponatremic group was consistent with both SIADH and RSW, while the nonhyponatremic group with increased FEurate would be consistent with RSW or normal controls depending on whether the FEurate was high or normal, respectively, figures 3, 4, table 1. (Maesaka et al, 1996, 1998, 1999, 2009) Based on these diagnostic possibilities, this study suffers first from a protocol-based elimination of patients with evidence of volume depletion as in RSW and failure to select the proper "control" and hyponatremic groups.

Ten patients with acquired immune deficiency syndrome with saline-responsive postural hypotension had CVP of $0 \mathrm{~cm}$ water, increased renin and aldosterone, hyponatremia, hypouricemia, elevated FEurate and $\mathrm{UNa}>40 \mathrm{mmol} / \mathrm{l}$, which collectively support the diagnosis of RSW. (Cusano et al, 1990; Maesaka et al, 1990) 


\subsection{Other pertinent studies}

In a retrospective study of 319 patients with SAH, 179 were hyponatremic and met criteria for SIADH and CSW. They found that $69.2 \%$ had SIADH, 6.5\% CSW and $4.8 \%$ a combination of SIADH and CSW. The volume status was determined by CVP measurements, presence of hypotension and undefined parameters. This report suffers by its retrospective design, paucity of data to support their diagnoses and reliance on CVP measurements that have little value in assessing ECV. (Sherlock et al, 2006) In a similar retrospective study that included a variety of intracranial diseases, they found $62 \%$ of patients to have SIADH, $26.7 \%$ hypovolemic, $16.6 \%$ drug-related, $4.8 \%$ CSW, $3.7 \%$ related to IV fluids and $2.7 \%$ a combination of CSW and SIADH. In both studies, the combination of SIADH and CSW in $4.8 \%$ and $2.7 \%$ of patients lacked supportive data to justify such a difficult and improbable diagnostic combination, especially in a retrospective study. (Sherlock et al, 2006, 2009)

\section{Renal salt wasting without clinical evidence of cerebral disease}

To add further confusion to the dilemma of differentiating SIADH from RSW, we recently published 2 cases of unequivocal RSW without cerebral disease. (Bitew et al, 2009; Maesaka et al, 2007) One very instructive case was a hyponatremic patient with a hip fracture, who was initially water-restricted for 7 days for an erroneous diagnosis of SIADH by an internist. While being water-restricted, her Uosm was $362 \mathrm{mosm} / \mathrm{kg}$ and UNa only $6 \mathrm{mmol} / \mathrm{L}$, which was initially construed as being consistent with hypovolemic hyponatremia of the prerenal type when $\mathrm{UNa}$ is typically low. A serum urate of $3.4 \mathrm{mg} / \mathrm{dL}$, however, was not consistent with prerenal azotemia and more consistent with SIADH and RSW. A volume-depleted patient with normal kidney function would have higher serum urate with a FEurate below $3 \%$. (Steele, 1969) Based on this reasoning, we performed a blood volume determination by gold standard radioisotope dilution methods and started saline infusion after baseline studies were collected. As expected the FEurate was markedly elevated at $29.6 \%$, which was consistent with both SIADH and RSW, but a 7.1\% reduction in blood volume was consistent with RSW. Increased baseline plasma renin and aldosterone and low normal ANP strongly supported the diagnosis of RSW. The low UNa of $6 \mathrm{mmol} / \mathrm{L}$ was attributed to a loss of appetite and reduced salt intake while being fluid-restricted to $750 \mathrm{ml} /$ day for 7 days prior to our studies. She was feeling weak and anorectic while being fluid-restricted and felt stronger with increased appetite approximately 18 hours after initiating saline infusion. The baseline Uosm of 362 mosm $/ \mathrm{kg}$ was attributed to a low medullary solute concentration resulting from low salt intake. A Uosm of $587 \mathrm{mosm} / \mathrm{kg}$ in the first urine passed after initiation of saline infusion supports our contention that the low salt intake decreased medullary solute concentration and decreased concentrating ability of the kidney, figure 1 . The UNa of $6 \mathrm{mmol} / \mathrm{L}$ reflects her low sodium intake and reduction of renal medullary solute content. Moreover, saline infusion progressively diluted the urine to a Uosm of 152 mosm/kg 13 hours after initiating saline therapy, at which time plasma ADH decreased from a baseline of $1.9 \mathrm{pg} / \mathrm{mL}$ to indeterminate levels. The elimination of the volume stimulus for $\mathrm{ADH}$ production by saline allowed the coexisting hypo-osmolality to inhibit $\mathrm{ADH}$ production and induce excretion of dilute urines as serum sodium increased from a baseline 120 to $138 \mathrm{mmol} / \mathrm{L}$ in the next 48 hours, figure 1. (Maesaka et al, 2007) 
Interestingly, the baseline FEurate of $29.6 \%$ increased further to a peak of $63 \%$ and $48 \%$ at the time of correction of the hyponatremia at $138 \mathrm{mmol} / \mathrm{L}$, figure 2 . The effect of saline on FEurate has been amply shown to be minimal. This persistently increased FEurate after correction of hyponatremia is consistent with RSW and not SIADH, to be discussed later. (Maesaka et al, 2007).

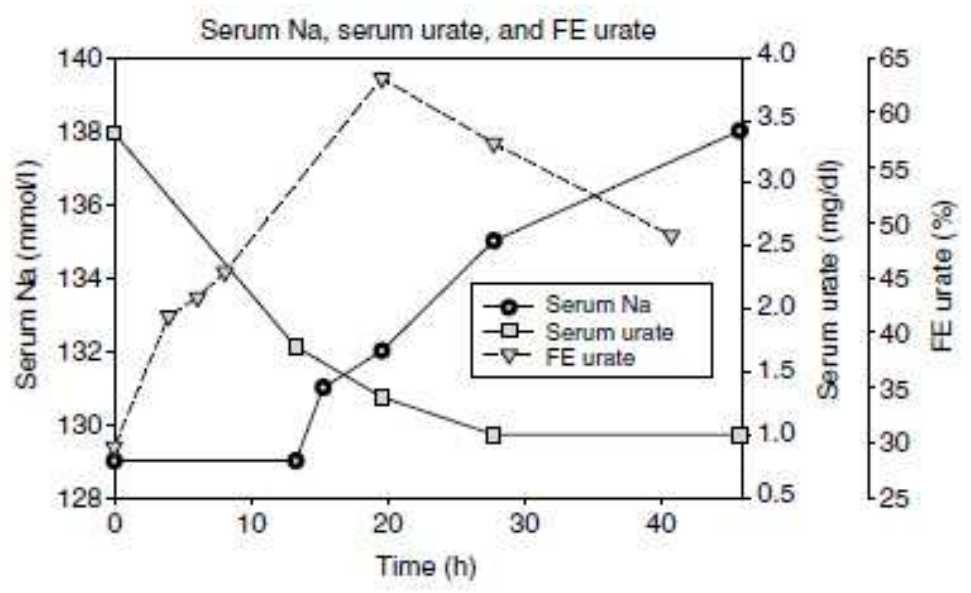

Fig. 2. Relationship between serum urate, serum sodium and FEurate during volume repletion with saline for 48 hours. Note that persistence of increased FEurate after correction of hyponatremia contrasts this to SIADH. Saline has been amply shown to have a meager effect on FEurate. (reproduced with permission from publisher)

In our view, this very instructive case followed predicted physiologic parameters for RSW and proved unequivocally the existence of RSW by collectively demonstrating the critical decrease in blood volume, increased plasma renin and aldosterone, low normal plasma ANP, appropriately increased plasma $\mathrm{ADH}$, which was inhibited by the combination of volume repletion and hypo-osmolality, increased free water excretion, and timely correction of hyponatremia. These compelling data proved that RSW can occur without evidence of clinical cerebral disease and that a low sodium intake will be associated with a low UNa in a patient with RSW. (Maesaka et al, 2007)

\section{Emerging value of determining FEurate}

Determination of serum urate in SIADH was first reported in 1971. Patients with SIADH had hypouricemia and increased FEurate, which normalized after correction of the hyponatremia. (Dorhout Mees et al, 1971) In 1979 Beck duplicated these findings, but compared serum urate in SIADH with other causes of hyponatremia. Except for only one overlapping value, there was complete separation of serum urate in SIADH from other causes of hyponatremia. (Beck, 1979) Correcting the hyponatremia by water restriction was accompanied by an increase in serum urate with normalization of a previously increased FEurate, figures 3, 4. (Beck, 1979) Beck concluded that the coexistence of hyponatremia and hypouricemia differentiated SIADH from most other causes of hyponatremia. This apparent simple method of differentiating SIADH from other causes of hyponatremia stimulated 
others to investigate this relationship and renal urate handling. Serum urate was consistently found to be decreased in SIADH and there was virtually no overlap or partial overlap with other causes of hyponatremia. (Assadi \& John, 1985; Passamonte 1984; Sonnenblick et al, 1988; Sorensen et al, 1988). FEurate was similarly increased in SIADH. (Assadi, 1985; Beck, 1979; Bitew, 2009; Decaux, 1990; Dorhout Mees ,1971; Drakakis, 2011; Weinberger et al, 1982; Sonnenblick, 1988; Sorenson, 1988) Several studies also demonstrated normalization or reduction of a previously increased FEurate after correction of hyponatremia by water restriction, figure 3, 4. (Assadi \& John, 1985; Beck, 1979; Decaux et al, 1990; DorhoutMees et al, 1971; Drakakis et al, 2011; Sonnenblick et al, 1988) Improvements in hypouricemia and increased FEurate after correction of hyponatremia, appear to be characteristic findings in SIADH, but the coexistence of hypouricemia and hyponatremia has not been found as useful as FEurate, figures 3, 4.

We encountered 5 patients, in whom an increased FEurate and hypouricemia persisted after correction of their hyponatremia by water-restriction, suggesting that these hyponatremic patients were pathophysiologically different from SIADH. (Maesaka et al, 1990) The first patient had metastatic pancreatic carcinoma with hypoalbuminemia, albumin $1.5 \mathrm{~g} / \mathrm{dL}$, edema, ascites, hypouricemia (serum urate $1.1 \mathrm{mg} / \mathrm{dL}$ ), increased FEurate, 34.2\%, hypophosphatemia, $1.7 \mathrm{mg} / \mathrm{dL}$, with increased FEphosphate, 29.1\%, UNa 99mmol/L and Uosm 716 mosm $/ \mathrm{kg}$. His FEurate remained persistently increased at $30.0 \%$ after correction of hyponatremia to $138 \mathrm{mmol} / \mathrm{L}$ by water-restriction. The edema, ascites and increased FEphosphate were inconsistent with SIADH and the collective findings were consistent with a variant of the Fanconi syndrome. The second case was a patient with bronchogenic carcinoma with a negative CT scan of brain, who presented with serum sodium of 116 $\mathrm{mmol} / \mathrm{L}$, saline-responsive postural hypotension, Uosm $323 \mathrm{mosm} / \mathrm{kg}$, UNa $42 \mathrm{mmol} / \mathrm{L}$, serum urate $2.0 \mathrm{mg} / \mathrm{dL}$, FEurate $26.5 \%$ and normal renal, adrenal and thyroid function. A diagnosis of SIADH was made on the basis of the report by Beck and he was waterrestricted with liberal salt supplementation, which was followed by significant weight loss, recurrence of his postural hypotension, weakness, postural dizziness, slurred speech, staggered gait and somnolence. His serum sodium finally corrected to $138 \mathrm{mmol} / \mathrm{l}$, and FEurate remained elevated at $14.7 \%$, despite being severely volume depleted. At this time, his Uosm was $980 \mathrm{mosm} / \mathrm{kg}$, UNa $181 \mathrm{mmol} / \mathrm{L}$ and he remained hypouricemic, serum urate $2.2 \mathrm{mg} / \mathrm{dL}$. He responded well to saline therapy with reversal of all of his symptoms. The increased FEurate and hypouricemia persisted after correction of his hyponatremia by water restriction and salt supplementation, suggesting that a persistently elevated FEurate and hypouricemia after correction of hyponatremia would be consistent with RSW. We found a persistent increase in FEurate and hypouricemia after correction of hyponatremia in three additional cases, one with bronchogenic carcinoma that had metastasized to brain, another with disseminated Cryptococcus that involved brain and uncomplicated Hodgkins disease with no clinical cerebral disease. All had normal renal adrenal and thyroid function. The hyponatremia, high UNa and concentrated urine were consistent with SIADH except for the persistent increase in FEurate. The hyponatremia, high UNa and concentrated urine were consistent with SIADH except for the persistent increase in FEurate, which was construed as being pathophysiologically different from SIADH and might serve to differentiate SIADH from RSW, figure 3, 4. Moreover, the absence of clinical cerebral disease in 3 of the 5 patients raised questions regarding the appropriateness of the term cerebral salt wasting. 


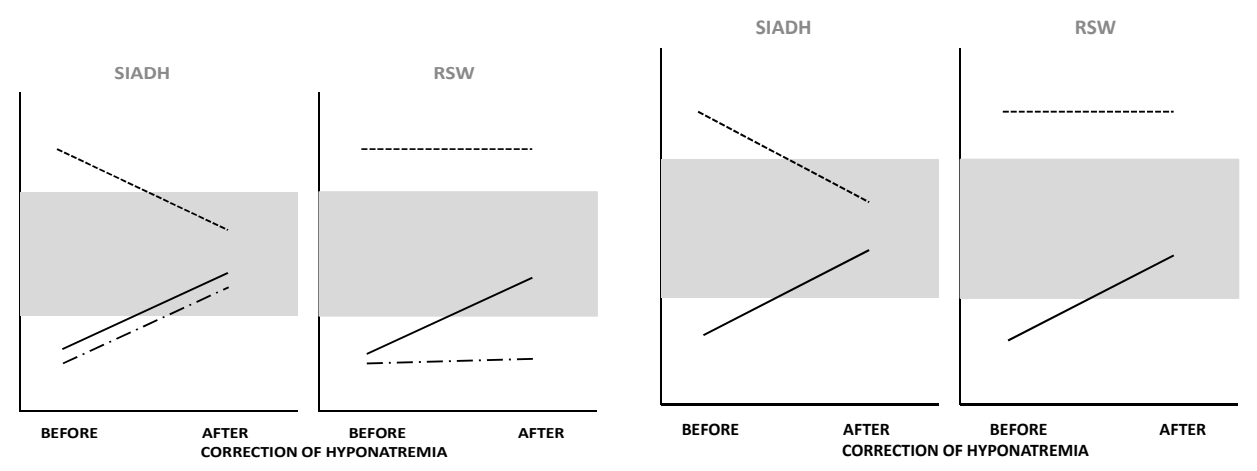

Fig. 3.

Fig. 4.

Fig. 3. and 4. Relationship between FEurate (FEUA........), serum urate (SUA — . - ) and serum sodium (SNa__ before and after correction of hyponatremia in SIADH and RSW. Shaded areas represent normal ranges. (Modified from Maesaka, 1999), Figure 3. Figure 4 is updated version with elimination of SUA, see test.

We prospectively evaluated 96 patients with AIDS. Sixteen patients had combined hyponatremia and hypouricemia, 21 were hypouricemic, and 19 of 23 patients studied had increased FEurate. Many had increased FEurate with normonatremia, which was consistent with RSW and not SIADH. All hyponatremic patients had high UNa and concentrated urines that were consistent with SIADH and RSW. Ten hyponatremic patients with saline responsive postural hypotension, $\mathrm{CVP}$ of $0 \mathrm{~cm} \mathrm{H}_{2} \mathrm{O}$ with high plasma renin and aldosterone collectively supported a diagnosis of RSW in AIDS. (Maesaka et al, 1990, 1990)

We extended our study to neurosurgical patients with diverse etiologies because 12 of 12 hypouricemia patients with AIDS had cortical atrophy of brain by CT scan. (Maesaka et al, 1990, 1992) The high incidence of RSW in neurosurgical patients suggested that RSW in AIDS might be due to their cerebral disease, so we prospectively studied urate metabolism in 29 neurosurgical patients of varying etiologies and 21 age and gender-matched controls. Seven patients were hypouricemic, 18 had FEurate $>10 \%$ and only 1 patient was hyponatremic. (Maesaka et al, 1992) We postulated that the increase in FEurate without hyponatremia was again consistent with RSW that was supported by the volume studies in neurosurgical patients. These observations solidified our notion that an increased FEurate with normonatremia may be consistent with RSW without a need to correct hyponatremia, figures 3, 4. Moreover, an increased FEurate was associated with serum urate $>5 \mathrm{mg} / \mathrm{dL}$, suggesting a greater value of FEurate over serum urate. (Maesaka et al, 1992, 1998, 2009)

A study of urate metabolism focused on other cerebral diseases because patients with AD were reported to have lower serum urate. (Kasa et al, 1989) Serum urate was lower and FEurate higher in 18 patients with $\mathrm{AD}$ as compared to 6 patients with multi infarct dementia and 11 age and gender-matched normal controls. (Maesaka et al, 1993) As in the neurosurgical study, only one patient with AD was hyponatremic. The increased FEurate with normonatremia suggested that demented patients with AD might have RSW and raised the question whether or not an isolated increase in FEurate with normonatremia without prior correction of a pre-existing hyponatremia would be consistent with RSW. 
One drawback to our proposal of determining FEurate after correction of hyponatremia to differentiate SIADH from RSW was the unpredictability of correcting the hyponatremia. We utilized the recommendation to treat hyponatremic patients with cerebral disease with hypertonic saline, regardless of whether or not the patient had SIADH or RSW. (Sterns et al, 2008) We increased serum sodium to $138 \mathrm{mmol} / \mathrm{L}$ within $2-3$ days with $1.5 \%$ and determined FEurate, being aware that saline had only a modest effect on FEurate and would not likely alter our results. (Cannon, 1970; Diamond, 1975; Maesaka \& Fishbane, 1998; Steele, 1974) We corrected hyponatremia within 2-3 days in 3 patients, who met usual criteria for SIADH, and found a previously increased FEurate to decrease to $<10 \%$ in all 3 patients. (Drakakis et al, 2011) Normalization of FEurate after correction of hyponatremia can be predictably achieved in 2-3 days by hypertonic saline and can be contrasted to a persistent increase in FEurate in RSW, figures 3, 4. The rate of correction can be controlled by monitoring serum sodium and adjusting free water intake to achieve the desired rate and extent of the correction of hyponatremia. These studies confirmed our notion that saline has a meager effect on FEurate by decreasing to normal levels during saline infusion. Under the proper circumstances of adequate cardiac function, hyponatremia can be corrected with $1.5 \%$ hypertonic saline in a predictably timely fashion to differentiate SIADH from RSW, figures 3, 4. (Drakakis et al, 2011)

\subsection{Pathophysiology of increased FEurate in SIADH and RSW}

The mechanisms by which FEurate increases in both SIADH and RSW are presently unexplained. The most prominent explanation has been the volume expansion that is seen in SIADH, but the saline infusion studies suggest that volume expansion has only a meager effect on FEurate. (Cannon et al, 1970; Diamond et al, 1975; Steele et al, 197) The $\mathrm{V}_{1}$ ADH receptor has been proposed as a cause for the increase in FEurate in SIADH after demonstrating an increase in FEurate by pitressin, and eliminating the effect by a $\mathrm{V}_{1}$-specific receptor inhibitor. (Decaux et al, 1996) This explanation is untenable because FEurate increased significantly at a time when normal subjects were hyponatremic during intranasal dDAVP, which lacks $\mathrm{V}_{1}$ activity, and by normalization of FEurate with correction of hyponatremia in SIADH when plasma ADH levels are still elevated. (Boer et al, 1987) It has been proposed that the defect in urate transport in SIADH was a result of an inhibition of the post secretory reabsorptive site for urate transport, based on the combination of the assumed secretory inhibition by pyrazinamide and decrease in post secretory reabsorption of urate by sulfapyrazone. (Weinberger et al, 1982) Studies in brush border membranes, however, demonstrate increased uptake of urate in the presence of pyrazinamide, suggesting that the decrease in urate excretion during pyrazinamide administration was a result of increased reabsorption and not inhibition of secretion. (Roch-Ramel et al, 1994) Until there is further clarification of the mechanisms and sites at which urate is transported, we must conclude that there is increased FEurate at a time when the patient is hyponatremic in SIADH, but the mechanism for this unique transport abnormality remains unclear. Lastly, the proposal that the chronic hyponatremia or hypo-osmolality contributed to the increase in FEurate in SIADH cannot be supported by the normal FEurate that has been reported in hyponatremia due to psychogenic polydipsia and more recently, $\mathrm{RO}$, to be discussed below. (Ali et al, 2009; Decaux et al, 2000; Imbriano et al, 2011) 
The increased FEurate in RSW, like that in SIADH, is presently not understood. There is a natriuretic factor(s) that is present in plasma and urine of patients with neurosurgical diseases and in plasma of patients with AD. As discussed above, this factor(s) has a major inhibitory effect on proximal tubule sodium transport. (Maesaka et al, 1993, 1993; Youmans \& Maesaka, 2011) The proximal tubule is the exclusive site of urate reabsorption and predominant site for phosphate. It would be interesting to speculate that the natriuretic factor might have a dose-dependent effect with different affinities for various transporters in the proximal tubule. The circulating factor could also explain the persistent increase in FEurate after correction of hyponatremia in RSW. Consistent with this speculation is our patient with metastatic pancreatic cancer who had transport defects for sodium, urate and phosphate that were interpreted as being consistent with the Fanconi syndrome. (Maesaka et al, 1990) For the moment, however, there are few insights into mechanisms by which FEurate increases in RSW.

\subsection{Hyponatremia with normal FEurate in reset osmostat}

Further appreciation of the emerging importance of determining FEurate in hyponatremic patients comes from our study of patients with RO or type C SIADH, which accounts for $36 \%$ of patients with SIADH. (Zerbe et al, 1980) It is characterized by euvolemia with normal renal, adrenal and thyroid function, hyponatremia resulting from ADH stimulation at a lower plasma osmolality or a $\mathrm{RO}$, having a reasonably normal diluting and concentrating capacity of urine, and maintaining normal sodium balance without correcting the hyponatremia. (Wall, 1993) They are typically untreated, but this approach poses a therapeutic dilemma because of our tendency to treat most if not all hyponatremics. (DeFronzo et al, 1976; Decaux et al, 2009; Elisaf et al, 1990; Hill et al, 1990; Kahn, 2003) We encountered 3 patients with hyponatremia and normal FEurate, who were noted to excrete urines with Uosm $<200$ mosm $/ \mathrm{kg}$, that was consistent with RO. Based on these findings, we decided to perform water-loading tests in nonedematous hyponatremic patients with normal FEurates without a dilute urine in a randomly collected urine, regardless of UNa or serum urate. (Imbriano, 2011) In this study of 14 patients, every nonedematous hyponatremic patient we encountered with a FEurate of $4-10 \%$ had $\mathrm{RO}$ as determined by Uosm $<200 \mathrm{mosm} / \mathrm{kg}$ on a random urine collection, 8 patients, or after a normal waterloading test, 6 patients. As is typical of RO, plasma ADH was undetectable in 4 patients studied during the water-loading test. Eleven patients had UNa $>20 \mathrm{mmol} / \mathrm{L}, 8$ were hypouricemic, yet all had a normal FEurate of $<10 \%$. Interestingly, 3 patients were on losartan and 2 on atorvastatin, which increase urine urate excretion and lower serum urate. (Milionis et al, 2004; Yamamoto et al, 2000) These data suggest that chronic hyponatremia does not increase FEurate as has been proposed as a contributing factor for the increased FEurate in SIADH. (Decaux et al 2000) Comorbid conditions were similar to those reported in $\mathrm{RO}$, including 2 patients without comorbidities. These and our other studies refine the proposal by Beck, that the coexistence of hyponatremia and hypouricemia differentiates SIADH from most other causes of hyponatremia, by stressing the greater value of FEurate over serum urate. (Beck, 1979; Maesaka et al, 1998, 2009) We concluded that RO occurs commonly, a normal FEurate in a nonedematous hyponatremic patient is highly suggestive of RO and FEurate has greater clinical utility than serum urate. (Imbriano et al, 2011) FEurate has a physiological basis for its derivation as compared to multiple factors that determine serum urate, including endogenous or exogenous purine sources, endogenous 
production and excretion via gut and urine. Moreover, the arbitrary definition of hypouricemia ranging from $1.5-4 \mathrm{mg} / \mathrm{dL}$ reflect the uncertainty of the value of serum urate as compared to well-defined parameters that have been established for FEurate. (Beck, 1979; Maesaka et al, 1990 e; Ramsdell \& Kelley, 1973) These studies also introduce the possibility that $\mathrm{RO}$ is pathophysiologically different from the more traditional SIADH by virtue of the normal FEurate and predictability of ADH responses to plasma osmolality.

\section{Change cerebral salt wasting to renal salt wasting}

The 2 cases of RSW without clinical cerebral disease were the impetus to propose replacing the designation, cerebral salt wasting, to renal salt wasting. (Bitew et al, 2009; Maesaka et al, 2007,2009 ) Based on these reports, cerebral salt wasting should be considered an outmoded and inappropriate designation; it should now be called RSW because RSW will be considered in any hyponatremic patient with or without cerebral disease. (Maesaka et al, 2009) Although we feel that RSW might be rare in patients without clinical cerebral disease, these cases of RSW without clinical cerebral disease support our contention that the true prevalence of RSW cannot be viewed as rare until future studies can accurately determine the prevalence of SIADH and RSW in patients with and without clinical evidence of cerebral disease. This would depend on our ability to differentiate SIADH from RSW. The volume studies indicate that RSW is much more common than SIADH in neurosurgical patients. We hope this expanded approach to hyponatremia and RSW will eliminate the inappropriate treatment of RSW by fluid restriction, which has been shown to increase morbidity and mortality when misdiagnosed as SIADH. (, Gutierrez \& Lin, 2009; Maesaka et al, 1990, 2007; Wijdicks et al, 1985)

\section{New approach to hyponatremia and how to differentiate SIADH from RSW}

The evaluation of the patient with hyponatremia traditionally starts with an assessment of $\mathrm{ECV}$, whether or not they are euvolemic, hypovolemic or hypervolemic. While this approach is fundamentally correct, we are again unable to assess accurately whether the patient is euvolemic or hypovolemic, realizing that hypervolemic patients can be identified by the presence of edema. We attempted to use UNa to support the volume approach by dividing the hypovolemic group into two categories, those with hypovolemia and normal kidney function, UNa $<20 \mathrm{mmol} / \mathrm{L}$ and those with $\mathrm{rSW}, \mathrm{UNa}>20 \mathrm{mmol} / \mathrm{L}$. Those with euvolemia or mainly SIADH, UNa is usually $>20 \mathrm{mmol} / \mathrm{L}$ and hypervolemia, $\mathrm{UNa}<20$ $\mathrm{mmol} / \mathrm{L}$. The major differential is a $\mathrm{UNa}$ of $>20 \mathrm{mmol} / \mathrm{L}$, which reverts back to differentiating SIADH from RSW. Differentiating the hypovolemic patient with normal renal function from hypervolemic hyponatremics, $\mathrm{UNa}<20 \mathrm{mmol} / \mathrm{L}$, is simplified by the presence or absence of edema. (Maesaka, 1996) The interpretation of UNa is also complicated by many factors, such as diuretics, the acutely vomiting patient with bicarbonaturia, acute and chronic kidney diseases and low UNa in the patient with SIADH and RSW on a low sodium diet. Limitations of UNa in the evaluation of patients with hyponatremia have been noted by others. (Chung et al, 1987)

Determinations of plasma renin and aldosterone can under proper circumstances contribute to differentiating SIADH from RSW. However, many factors can affect one or both values, such as the use of diuretics, ACE inhibitors, ARB, NSAIDS, heparin or saline.(Mulatero et al, 
2002) Even under ideal circumstances the delay in obtaining these results does not assist us on first encounter with the patient.

It is evident that the evaluation of the volume status or determining UNa has limited utility. This dilemma persists to this day on first encounter with the nonedematous hyponatremic patient. We developed an algorithm, which emphasizes FEurate in the evaluation of hyponatremia, table 1 . We propose with supporting data to determine FEurate in any nonedematous patient with hyponatremia. If the FEurate is $5-10 \%$, we should consider psychogenic polydipsia, $\mathrm{RO}$ and prerenal causes, such as congestive heart failure, cirrhosis, nephrosis and pre eclampsia, or hypovolemia with normal renal function. Psychogenic polydipsia can be eliminated from the history of increased water intake and very dilute urines. (Ali et al, 2009) Edematous states can be ruled out by the presence of edema. The major obstacle might be the hypovolemic patient with normal renal function and classic prerenal azotemia, but the low mean FEurate of $2.85 \%$, possibly high serum urate and $\mathrm{UNa}$ $<20 \mathrm{mmol} / 1 \mathrm{might}$ assist in differentiating this group from RO. (Steele, 1969) In patients who do not fall into the groups mentioned, we would consider $\mathrm{RO}$ and search diligently for a dilute urine in a random urine collection. In the absence of a dilute random urine, we do not recommend performing a water-loading test to prove the diagnosis of RO. (Imbriano et al, 2011) We would instead treat them with water restriction and salt supplementation, however unsuccessful they are, and consider using ADH receptor inhibitors, vaptans.

If the FEurate exceeds preferably $12 \%$, there are three possibilities to consider, SIADH, RSW, thiazide diuretics and drugs that induce an SIADH-like picture. Thiazide diuretics and neurotropics can be readily eliminated by a proper history so the major differential would be SIADH and RSW. We propose to correct serum sodium either by water-restriction with salt supplementation or 1.5\% hypertonic saline and determine FEurate. (Drakakis et al, 2011) If FEurate corrects to $<10 \%$, we would proceed with treatment for SIADH or if it exceeds $10 \%$, preferably $>12 \%$, we would treat the patient for RSW with saline. The question represented as dotted lines in table 1 depends on whether the coexistence of increased FEurate with normonatremia would be diagnostic of RSW. While there are supporting data to suggest this to be a valid conclusion, especially in patients with neurosurgical diseases, future studies will hopefully provide further insights into this relationship. Because neurosurgical patients are routinely treated with hypertonic saline, an increased FEurate with normonatremia or hypernatremia would be suggestive of RSW, see above. We have found this algorithm to be superior to the previous approach as discussed above and expect to make further refinements to this algorithm in the future.

\section{Treatment of the hyponatremic patient with SIADH and RSW}

The increasing reports of significant symptoms being attributed to even mild hyponatremia not only shed light on a long unrecognized phenomenon, but introduce the need for some urgency in developing adequate treatment strategies for a condition with diverse etiologies and divergent therapeutic goals. Treatment, however, has undergone a period of uncertainty due to adverse outcomes that are related to delays in treatment and overcorrection of chronic hyponatremia. (Berl et al, 1990) The approach to methods of correction in different clinical conditions will be limited to SIADH and RSW and the reader is referred to broader reviews of treating hyponatremia. (Stern et al, 2009; Verbalis et al, 2007) As discussed earlier, foremost among the diagnostic and therapeutic dilemma is the need to 
differentiate SIADH from RSW in order to fulfill divergent therapeutic goals. It is well known that severe hyponatremia can cause neurologic symptoms, such as irritability, seizures and even apnea, but more subtle alterations in memory and judgment, unsteady gait and even falls have been associated with mild hyponatremia that have responded to treatment of their hyponatremia. (Berl et al, 2010; Decaux et al, 2006, 2009; Gankam Kengne et al, 2008; Renneboog et al, 2006) It is, therefore, pertinent to ask whether "asymptomatic hyponatremia exists". (Schrier, 2010) One of the most alarming outcomes has been the descriptions of a four-fold increase in falls that have been attributed to mild hyponatremia, mean serum sodium $131 \mathrm{mmol} / \mathrm{L}$, in the elderly. (Renneboog et al, 2006; Gankam Kengne et al, 2008) There is, therefore, a movement to consider treating all hyponatremics, including the infusion of hypertonic saline to treat hyponatremic patients with brain diseases to avoid brain edema regardless of whether or not they have SIADH or RSW. (Sterns \& Silver, 2008)

\section{Approach to Hyponatremia}

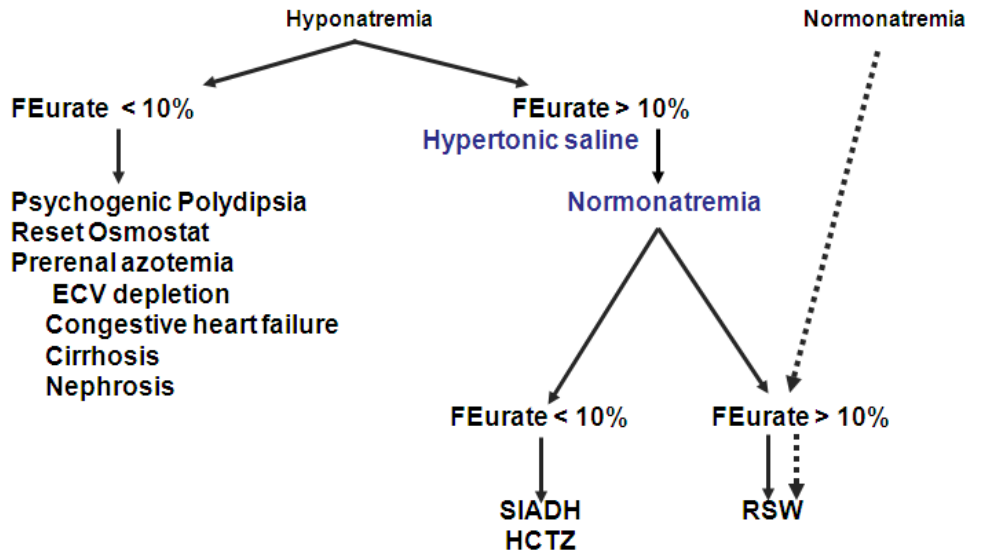

Table 1. New approach to hyponatremia based on FEurate. Normonatremia and FEurate without hyponatremia needs further verification, dotted line.

The standard approach to treating hyponatremia depends on the etiology of the hyponatremia. Patients with edematous causes of hyponatremia such as heart failure, cirrhosis or nephrosis are treated with a combination of water-restriction, low salt diet, diuretics and the ADH inhibitors or vaptans. Vaptans are clearly indicated in edematous states and are contraindicated in hypovolemic patients. Of the available vaptans, conivaptan inhibits the $V_{1 A}$ and $V_{2}$ receptor for $A D H$ and tolvaptan the $V_{2}$ receptor. Conivaptan is administered only intravenously and inhibits CYP3A4 so its administration must consider other agents that might be metabolized by this pathway and potentially increase blood levels of conivaptan. (Sterns et al, 2009) Because conivaptan inhibits the $\mathrm{V}_{1 \mathrm{~A}}$ receptor, which has vasopressive activity, it is not indicated for treatment of hyponatremic cirrhotics. (Sterns et al, 2009) SIADH and RO are treated by water-restriction with salt supplementation and hypertonic saline in patients with brain disease, but the vaptans appear to be promising for both conditions. Vaptans have been shown to increase serum sodium successfully and improve symptoms attributed to non hypovolemic hyponatremia, including better 
symptomatic improvement in patients with SIADH. (Berl et al, 2010; Schrier et al, 2006; Verbalis et al, 2011) Patients should not be water-restricted while being treated with the vaptans except under very unusual circumstances to avoid rapid correction of hyponatremia. Serum sodium should be monitored at least within 8 hours of initiating vaptan therapy, but we recommend repeating serum sodium determinations earlier if the patient increases urine output soon after starting vaptan therapy. (Berl et al, 2010) The increase in urine output suggests that $\mathrm{ADH}$ receptor inhibition is occurring rapidly and the resulting increase in free water excretion would correct sodium rapidly thereafter, hence a recommendation to determine serum sodium at this time. Over-correction of hyponatremia can be avoided by closely matching the increased urine volume or if too rapid, by the administration of free water and/or intranasal dDAVP.

The treatment of $\mathrm{SIADH}$, including $\mathrm{RO}$, traditionally starts with the treatment of the associated clinical condition, fluid restriction to $<1000 \mathrm{ml} /$ day, salt supplementation, occasionally diuretics, demeclocyline and ADH inhibitors. The correction of hyponatremia in SIADH by fluid restriction and/or salt supplementation has been slow and often incomplete or unsuccessful. Treatment of RO has been generally unsuccessful to the point of not recommending any treatment for these patients. The use of vaptans in SIADH can be justified by their hypervolemic state, but it is uncertain whether patients with RO are similarly volume expanded. Although an increase in volume makes intuitive sense, volume studies have not been performed in patients with RO to justify use of vaptans. Our ability to identify patients with $\mathrm{RO}$ by virtue of a normal FEurate will uncover this common cause of hyponatremia and test the efficacy of vaptans in this therapeutically challenging group. (Imbriano et al, 2011)

In contrast to the difficulty of treating patients with SIADH or RO, the treatment of RSW is simple. Eliminating the appropriate volume stimulus for $\mathrm{ADH}$ secretion in this disorder with saline will allow the coexisting hypo-osmolality to inhibit ADH secretion, increase free water excretion and correct the hyponatremia. (Bitew et al, 2009; Maesaka et al, 2007) Use of vaptans is obviously contraindicated in these volume depleted patients. While the rationale for increasing salt and water intake in patients with RSW is obvious, we are again confronted with our inability to differentiate SIADH from RSW with any degree of certainty. This therapeutic dilemma has been partially resolved by the recommendation to treat hyponatremic patients with acute neurological/neurosurgical diseases with hypertonic saline to prevent the complications associated with brain edema of multiple causes. (Sterns \& Silver, 2008 and et al, 2009) As discussed earlier, RSW is more common than SIADH in neurosurgical diseases and the use of hypertonic saline not only reduces brain edema but has other advantages, such as treating their volume depletion. (Sterns \& Silver, 2008) Administration of hypertonic saline prevents hyponatremia from occurring so an increased FEurate would be consistent with RSW. (Youmans \& Maesaka, 2011). A timely correction of an existing hyponatremia by judicious use of hypertonic saline can also differentiate SIADH from RSW, whether FEurate normalizes or remains increased, respectively, figures 3, 4.

Hyponatremic patients outside of the neurology/neurosurgical ICU, including those with nonedematous hyponatremia with or without cerebral disease, need to be evaluated for etiology of their hyponatremia, as discussed above. Following the algorithm in table 1 has been useful in our hands. Therapy will depend on the etiology of the hyponatremia. In those with increased FEurate, the diagnostic dilemma of differentiating SIADH from RSW must 
be extended to those without clinical cerebral disease. This diagnostic and dependent therapeutic dilemma will persist until we have a mindset to consider RSW in these patients and develop a better diagnostic approach to solving this dilemma. Recommendations to determine FEurate in normonatremic patients have not been resolved except to include it as a routine measurement in any patient with acute brain disease and demented patients with AD.

In patients with symptomatic hyponatremia such as muscular irritability, altered mental status or seizures, the patient should be treated with hypertonic saline to increase serum sodium by $4-6 \mathrm{mmol} / 1$ over 4 hours and then slowly thereafter. (Sterns \& Silver, 2008) Although it is safe to increase serum sodium to normal values in conditions such as in acute and documented water intake, marathon runners, that cause acute hyponatremia, we recommend gradual improvement in all patients with hyponatremia to avoid any contributions rapid correction might add to circumstances in which osmotic demyelination might occur irrespective of their sodium, such as in malnourished patients or those with liver disease. (Almond et al, 2005, Sterns \& Silver, 2008) We favor a conservative approach to the correction of chronic hyponatremia by increasing serum sodium $<10 \mathrm{mmol} / \mathrm{l} / 24 \mathrm{hrs}$ with slower rates for patients with severe malnutrition and cirrhosis to avoid osmotic demyelination.

\section{Summary}

The present chapter hopefully provided the following important insights and new directions in our understanding of RSW:

1. an appreciation of the diagnostic and therapeutic dilemma that exists for SIADH and RSW.

2. provided an objective review of how the controversy over the relative prevalence of SIADH and RSW evolved.

3. emphasized our inability to assess accurately the state of ECV as being the root of this enigmatic controversy and how the overlapping features of both syndromes make it virtually impossible to differentiate SIADH from RSW on first encounter.

4. reviewed the relative merits by which we determine ECV.

5. RSW is much more common than SIADH in neurosurgical patients and RSW can occur in the absence of hyponatremia.

6. although FEurate is increased in both SIADH and RSW, FEurate can differentiate one syndrome from the other by reverting to normal in SIADH and being persistently increased after correction of hyponatremia.

7. the demonstration of natriuretic activity in plasma of neurosurgical and in the plasma and urine of Alzheimer disease patients with increased FEurate and normonatremia introduces the possibility that an increased FEurate with normonatremia might be diagnostic of RSW.

8. the natriuretic factor probably contributes to RSW, has its major effect in the proximal tubule where urate is exclusively transported and is not A/BNP.

9. a normal FEurate in patients with nonedematous hyponatremia is highly suggestive of $\mathrm{RO}$ and identifies a common and overlooked disorder.

10. the normal FEurate and predictability of $\mathrm{ADH}$ responses suggest that $\mathrm{RO}$ might represent a group that is pathophysiologically different from SIADH. 
11. we provide a useful algorithm that utilizes FEurate as central to our approach to evaluating patients with hyponatremia.

12. based on our two cases of renal salt wasting without clinical cerebral disease, we propose eliminating the term cerebral salt wasting in favor of renal salt wasting

\section{References}

Abuelo JG: Normotensive ischemic acute renal failure. (2007) N Eng Jour Med,357,pp.797-8

Ali N, Imbriano L, Miyawaki N, \& Maesaka JK.(2009) 66-year-old male with Hyponatremia. Kidney Int,76,pp.233-234

Almond CS, Shin AY, Fortescue EB, Mannix RC, Wypij D, Binstadt BA, Duncan CN, Olson DP, Salerno AE, Newburger JW, \& Greenes DS. (2005) Hyponatremia among runners in the Boston Marathon. N Engl J Me,;352, pp.1550-1556

Arieff AI, Llach F, \& Massry SG. (1976) Neurological manifestations and morbidity of hyponatremia: correlation with brain water and electrolytes. Medicine (Baltimore),55(2),pp.121-129.

Assadi FK, \& John EG. (11985) Hypouricemia in neonates with syndrome of inappropriate secretion of antidiuretic hormone. Ped Res,19,pp.424-427.

Beck LH. (1979) Hypouricemia in the syndrome of inappropriate secretion of antidiuretic hormone. N Engl J Med,301,pp.528-530

Berl T, Quittnat-Pelletier F, Verbalis JG, Schrier RW, Bichet DG, Ouyang J, \& Czerwiec FS. (2010) SALTWATER Investigators. Oral tolvaptan is safe and effective in chronic hyponatremia. J Am Soc Nephrol,21(4),pp.705-712

Berl T, Quittnat-Pelletier F, Verbalis JG, Schrier RW, Bichet DG, Ouyang J, \& Czerwiec FS; SALTWATER Investigators. (2010) Oral tolvaptan is safe and effective in chronic hyponatremia. J Am Soc Nephrol, 21,pp.705-712

Berl T. (1990) Treating hyponatremia: damned if we do and damned if we don't. Kidney Int. 37(3),pp.1006-1018.

Bitew S, Imbriano L, Miyawaki N, Fishbane S, \& Maesaka JK. (2009) More on renal salt wasting without cerebral disease, response to saline infusion. Clin J Amer Soc Nephol,4:309-315

Boer WH, Koomans HA, \& Dorhout Mees EJ. (1987) Lithium clearance during the paradoxical natriuresis of hypotonic expansion in man. Kidney In, 32,pp.376-381

Brimioulle S, Oretiani-Jimenez C, Aminian A, \& Vincent JL.(2008) Hyponatremia in neurological patients: cerebral salt wasting versus inappropriate antidiuretic hormone secretion. Intensive Care Med,34,pp.125-131

Burnett JC Jr, Kao PC, Hu DC, Heser DW, Heublein D, Granger JP, Opgenorth TJ, \& Reeder GS. (1986) Atrial natriuretic peptide elevation in congestive heart failure in the human. Science,7;231(4742),pp.1145-1147.

Cannon PJ, Svahn DS, \& Demartini FE: (1970) The influence of hypertonic saline infusions upon the fractional reabsorption of urate and other ions in normal and hypertensive man. Circulation,41,pp.97-108..

Chung HM, Kluge R, Schrier RW, \& Anderson RJ. (1987) Clinical assessment of extracellular fluid volume in hyponatremia. Am J Med,83,pp.905-908

Cort JH. (1954) Cerebral salt wasting. Lancet(1),pp.752-754

Cusano AJ, Thies HL, Siegal FP, Dreisbach AW, \& Maesaka JK (1990) Hyponatremia in patients with acquired immunodeficiency syndrome. Jour AIDS,3,pp.949-953 
de Zeeuw D, Janssen WM, \& de Jong PE. (1992) Atrial natruretic factor: its (patho) physiological significance in humans. Kidney Int,41,pp. 1115-1133

Decaux G, Namias B, Gulbis B, \& Soupart A: (1996) Evidence in hyponatremia related to inappropriate secretion of $\mathrm{ADH}$ that $\mathrm{V} 1$ receptor stimulation contributes to the increase in renal uric acid clearance. J Am Soc Nephrol,7,pp. 805-810.

Decaux G, Prospert F, Soupart A, \& Musch W. (2000) Evidence that chronicity of hyponatremia contributes to the high urate clearance observed in the syndrome of inappropriate secretion of antidiuretic hormone. Am J Kidney Dis 36,pp.745-751

Decaux G. (2006) Is asymptomatic hyponatremia really asymptomatic? Am J Med,119 (7 Suppl 1),pp.S79-S82.

Decaux G. (2009) The syndrome of inappropriate secretion of antidiuretic hormone (SIADH). Semin Nephrol,29,pp.239-256.

DeFronzo RA, Goldberg M, \& Agus Z. (1976) Normal diluting capacity in hyponatremic patients. Reset Osmostat or a variant of the syndrome of inappropriate hormone secretion. Ann Int Med, 84,pp.538-542

Diamond H, \& Meisel A. (1975) Influence of volume expansion, serum sodium, and fractional excretion of sodium on urate excretion. Pflugers Arch,356,pp.47-57.

Dorhout Mees EJ, Blom van Assendelft P, \& Nieuwenhuis MG: (1971) Elevation of urate clearance caused by inappropriate antidiuretic hormone secretion. Acta Med,189,pp.69-72

Dorhout Mees EJ. (1990) History of the "lithium concept". Kidney Int Suppl,28,pp.S2-S3.

Drakakis J, Imbriano L, Miyawaki N, Shirazian S, \& Maesaka. (2011) Normalization of fractional excretion of urate (FEurate) after correction of hyponatremia differentiates SIADH from cerebral/renal salt wasting (RSW). Abst. Annual Mtg Am Soc Nephrol, Philadelphia, PA, USA

Elisaf MS, Konstantinides A, \& Stamopoulos KC. (1996) Chronic hyponatremia due to reset osmostat in a patient with colon cancer. Am J Nephrol,16,pp.349-351.

Ellison DH, \& Berl T. (2007) The syndrome of inappropriate antidiuresis. N Engl J Med,356,pp.2064-207

Eräranta A, Kurra V, Tahvanainen AM, Vehmas TI, Kööbi P, Lakkisto P, Tikkanen I, Niemelä OJ, Mustonen JT, \& Pörsti IH. (2008) Oxonic acid-induced hyperuricemia elevates plasma aldosterone in experimental renal insufficiency. $J$ Hypertens, 26(8),pp.1661-8.

Fenske W, Stork S, Koschker AC, Blechschmidt A, Lorenz D, Wortmann S, \& Allolio B. (2008)Value of fractional uric acid excretin in differential diagnosis of hyponatremic patients on diuretics. J. Clin Endocrinol Metab,93,pp.2991-2997

Fichman MP, Micheldakis AP, \& Horton R. (1974) Regulation of aldosterone in the syndrome of inappropriate antidiuretic hormone secretion (SIADH): J Clin Endocrinol Metab,39,pp.136-144

Gankam Kengne F, Andres C, Sattar L, Melot C, \& Decaux G. (2008) Mild hyponatremia and risk of fracture in the ambulatory elderly. QJM,101(7),pp.583-588.

Gödje O, Peyerl M, Seebauer T, Lamm P, Mair H, \& Reichart B. (1998) Central venous pressure, pulmonary capillary wedge pressure and intrathoracic blood volumes as preload indicators in cardiac surgery patients. Eur J Cardiothorac Surg,13(5),pp.533539

Gutierrez OM, \& Lin HY: (2007) Refractory Hyponatremia. Kidney Int,71,pp.79-82 
Hill RA, Uribarri J, Mann J, \& Berl T. (1990) Altered water metabolism in tuberculosis: role of vasopressin. Am J Med,88,pp.357-364.

Hollenberg NK. (1980) Set point for sodium homeostasis: Surfeit, deficit, and their implication. Kidney Int,17,pp.423-429.

Hoorn EJ, Hoffert JD, \& Knepper MA. (2005) Combined proteomics and pathways analysis of collecting duct reveals a protein regulatory network activated in vasopressin escape. J Am oc Nephrol, 16, pp.2852-2863

Hoorn EJ, Van Der Lubbe N, Zietse R. (2009) SIADH and hyponatremia: why does it matter. NDT plus (suppl 3),pp. iii5-iii11

Imbriano LJ, Ilamathi E, Ali NM, Miyawaki N, \& Maesaka JK. (2011) Normal fractional urate excretion identifies hyponatremic patients with reset osmostat (J. Nephrol In Press)

Jaenike JR, \& Waterhouse C. (1961) The renal response to sustained administration of vasopressin and water in man. J Clin Endocrinol Metab,21,PP.231-242

Jensen KT, Carstens J, \& Pedersen EB. (1998) Effect of BNP on renal hemodynamics, tubular function and vasoactive hormones in humans, Am J Physiol,274, pp. F63-F72.

Kahn T. (2003) Reset Osmostat and salt and water retention in the course of severe hyponatremia. Medicine,82,pp.170-176

Kasa M, Bierma TJ, Waterstraat F Jr, Corsaut M, \& Singh SP. (1989) Routine blood chemistry screen: a diagnostic aid for Alzheimer's disease. Neuroepidemiology,8(5)pp.254-256

Leaf A, Bartter FC, Santos RF, \& Wrong O. (1953) Evidence in man that urinary electrolyte loss induced by pitressin is a function of water retention. J Clin Invest,32,pp.868-878.

Leyssac PP, Holstein-Rathlou NH, Skøtt P, \& Alfrey AC. (1990) A micropuncture study of proximal tubular transport of lithium during osmotic diuresis. Am J Physiol,258(4 Pt 2),pp.F1090-F1095.

Maack T, Marion DN, Camargo MJ, Kleinert HD, Laragh JH, \& Vaughan ED Jr. (1984) Atlas SA: Effects of auriculin (atrial natriuretic factor) on blood pressure, renal function, and the renin-aldosterone system in dogs. Am J Med,77(6),pp.1069-1075.

Maesaka JK, \& Fishbane S. (1998) Regulation of renal urate excretion: a critical review. Am J Kidney Dis,32,pp.917-933

Maesaka JK, Batuman V, Yudd M, Sale M, Sved AF, \& Venkatesan J. (1990) Hyponatremia and hypouricemia: Differentiation from the syndrome of inappropriate secretion of antidiuretic hormone. Clin Nephrol,33,PP.174-178

Maesaka JK, Cusano AJ, Thies HL, Siegal FP, \& Dreisbach A. (1990) Hypouricemia in acquired immunodeficiency syndrome. Am. J. Kidney Dis,15,pp.252-257

Maesaka JK, Gupta S, \& Fishbane S. Cerebral salt wasting syndrome: does it exist? Nephron 82:100-109, 1999

Maesaka JK, Imbriano L, Ali N, \& Ilamathi E. (2009) Mini Review. Is it cerebral or renal salt wasting? Kidney Int,76,pp.934-938

Maesaka JK, Miyawaki N, Palaia T, Fishbane S, \& Durham J. (2007) Renal salt wasting without cerebral disease: value of determining urate in hyponatremia. Kidney Int,71,pp.822-826

Maesaka JK, Venkatesan J, Piccione JM, Decker R. Dreisbach AW, \& Wetherington J. (1993) Plasma natriuretic factor(s) in patients with intracranial disease, renal salt wasting and hyperuricosuria. Life Sci,52,pp.1875-1882

Maesaka JK, Venkatesan J, Piccione JM, et al. (1992) Abnormal renal urate transport in patients with intracranial disease. Am J Kidney Dis,19,pp.10-15 
Maesaka JK, Wolf-Klein G, Piccione JM, \& Ma CM. (1993) Hyporuicemia, abnormal renal tubular urate transport, and plasma natriuretic factor(s) in patients with Alzheimer's disease. J Am Geriatr Soc, 41,pp.501-506

Maesaka JK. (1996) An expanded view of SIADH, hyponatremia, and hypouricemia. Editorial. Clin Neph,46,pp.79-83

Marik PE, Baram M, \& Vahid B. (2008) Does central venous pressure predict fluid responsiveness? A systematic review of the literature and the tale of seven mares. Chest,134,pp.172-178

McCance RA. (1936) Experimental sodium chloride deficiency in man. Proc Roy Soc, London, ser. B 119,pp.245-268, 1936.

Milionis HJ, Kakafika Al, Tsouli SG, Athyros VG, Bairaktari ET, Seferiadis KI, \& Elisaf MS.(2004) Effects of statin treatment on uric acid homeostasis in patient with primary hyperlipidemia. Am. Heart J, 148,pp. 635-640

Mulatero P, Rabbia F, Milan A, Paglieri C, Morello F, Chiandussi L, \& Veglio F. (2002) Drug effects on aldosterone/plasma renin activity ratio in primary aldosteronism. Hypertension, 40,pp.897-902

Nelson PB, Seif SM, Maroon JC, \& Robinson AG. (1981) Hyponatremia in intracranial disease: Perhaps not the syndrome of inappropriate secretion of antidiuretic hormone (SIADH). J Neurosurg,55,pp.938-941

Oh MS, \& Carroll HS. (1999) Cerebral salt-wasting syndrome, we need better proof of its existence. Nephron, 82,pp.110-114

Oliver WJ, Cohen EL, \& Neel JV. (1975) Blood pressure, sodium intake, and sodium related hormones in the Yanomamo Indians, a "No-Salt" culture. Circulation,52,pp.146-151.

Palmer BF. (2003) Hyponatremia in patients with central nervouos system disease: SIADH versus CSW. Trends endocrinol metab,14,pp.182-187

Passamonte PM. (1984) Hypouricemia, inappropriate secretion of antidiuretic hormone, and small cell carcinoma of the lung. Arch Int Med,144,pp.1569-1570

Peters JP, Welt LG, Sims EAH, Orloff J, \& Needham J. (1950) A salt-wasting syndrome associated with cerebral disease. Trans Assoc Am Physicians 63,pp. 57-64

Ramsdell CM, \& Kelley WN. (1973) The clinical significance of hypouricemia. Ann Intern Med,78,pp.239-242.

Renneboog B, Musch W, Vandemergel X, Mantu MU,\& Cedaux G. (2006) Mild chronic hyponatremia is associated with falls, unsteadiness, and attention deficits. Am J Med,119,pp.711-718.

Richards AM, \& Crozier IG. (1989) Physiological role of atrial natriuretic peptide. Int J Cardiol, 25,pp.141-144.

Robertson GL, \& Ganguly A. (1986) Osmoregulation and baroregulation of plasma vasopressin in essential hypertension. Cardiovasc Pharmacol,8 Suppl 7,pp.S87-S91.

Roch-Ramel F, Guisan B.,\& Schild L. (1996) Indirect coupling of urate and paminohippurate transport to sodium in human brush-border membrane vesciles. Am J Physiol,270,pp.F761-F68

Schneditz D. (2006) The arrow of bioimpedance. Kidney Int,69,pp.1492-1493

Schrier R. (2010) Does 'asymptomatic hyponatremia' exist? Nat Rev Nephrol,6,pp.1

Schrier RW, Gross P, Gheorghiade M, Berl T, Verbalis JG, Czerwiec FS, \& Orlandi C; SALT Investigators. (2006)Tolvaptan, a selective oral vasopressin V2-receptor antagonist, for hyponatremia. N Engl J Med,355, pp. 2099-112 
Schwartz WB, Bennett W, \& Curelop S. (1957) A syndrome of renal sodium loss and hyponatremia probably resulting from inappropriate secretion of antidiuretic hormone. Am J Med,23,pp.529-542

Shannon JA. (1936) Glomerular filtration and urea excretion in relation to urine flow in the dog. Am J Physiol,117,pp.206-225.

Sherlock M, O'Sullivan E, Agha A, Behan LA, Rawluk D, Brennan P, Tormey W, \& Thompson CJ. (2006) The incidence and pathophysiology of hyponatremia in subarachnoid hemorrhage. Clin Endocrinol,64,pp.250-254

Sherlock M, O'Sullivan E, Agba A,k Behan LA, Owens D, Finucane F, Rawluck D, Tormey W, \& Thompson CJ. (2009) Incidence and pathophysiology of severe hyponatremia in neurosurgical patients. Postgrad Med,85,pp.171-175

Sing S, Bohn D, Cariotti AP, Cusimano M, Rutka JT, \& Halperin ML. (2002) Cerebral salt wasting: Truths, fallacies, theories, and challenges. Crit Care Med,30,pp.2575-2579

Sivakumar V, Rajshekhar V, \& Chandy MJ. (1994) Management of neurosurgical patient with hyponatremia and natriuresis. Neurosurgery,43,pp.269-274

Sonnenblick M, \& Rosin A. (1988) Increased uric acid clearance in the syndrome of inappropriate secretion of antidiuretic hormone. Isr J Med Sci,24,pp.20-23

Sonnenblick M, \& Rosin AJ. (1986) Significance of the measurement of uric acid fractional clearance in diuretic induced hyponatremia. Postgrad Med J,62(728),pp.449-452

Sorensen JB, Osterlind K, Kristiansen PEG, Hammer M, \& Hansen M. (1988) Hypouricemia and urate excretion in small cell lung carcinoma patients with syndrome of inappropriate antidiuresis. Acta Oncol,27,pp.351-355.

Steele A, Gowrishankar M, Abrahamson S, Mazer CD, Feldman RD, \& Halperin ML. (1997) Postoperative hyponatremia despite near-isotonic saline infusion: a phenomenon of desalination. Ann Intern Med,126,pp.20-25

Steele T. (1969) Evidence for altered renal urate reabsorption during changes in volume of the extracellular fluid. J Lab Clin Med,74,pp.288-299

Steele TH. Oppenheimer S: Factors affecting urate excretion following diuretic administration in man. Am J Med 1969; 47: 564-574

Sterns RH, \& Silver SM. (2008) Cerebral salt wasting versus SIADH: what difference? J Am Soc Nephrol,18(2),pp.194-196

Sterns RH, Nigwekar SU, \& Hix JK. (2009) The treatment of hyponatremia. Sem Nephrol,29(3),pp.282-299.

Strauss MB, Lamdin E, Smith P, \& Bleifer DJ. (1958) Surfeit and deficit of sodium. Arch Int Med,102,pp.527-536.

Traynor TR, Smart A, Briggs JP, \& Schnermann J. (1999) Inhibition of macula densastimulated renin secretion by pharmacological blockade of cyclooxygenase-2. Am J Physiol,277(5 Pt 2),pp.F706-F710.

Valtin H: (1997) Renal dysfunction: Disorders of Na+ balance. Edema first edition: Mechanism involved in the fluid and solute imbalance. Little Brown and company (Inc), Boston,pp.58-59.

Verbalis JG, Adler S, Schrier RW, Berl T, Zhao Q, \& Czerwiec FS: SALT Investigators. (2011) Efficacy and safety of oral tolvaptan therapy in patients with the syndrome of inappropriate antidiuretic hormone secretion. Eur J Endocrinol 164,pp. 725-732 
Verbalis JG, Goldsmith SR, Greenberg A, Schrier RW, \& Sterns RH. (2007) Hyponastremia treatment guidelines 2007: Expert Panel Recommendations. Am J Med,120,pp.S1S21

Vogel JH. (1963) Aldosterone in the cerebral salt wasting. Circulation,127,pp.44-50.

Wall BM, Crofton JT, \& Share L. (1992) Chronic hyponatremia due to resetting of the osmostat in a patient with gastric carcinoma. Am J Med 1992,93,pp.223-228

Wall BM. (1993) Water loading test in the reset osmostat variant of SIADH. Am J Med.94,pp.343.

Weinberger A, Santo M, Solomon F, Shalit M, Pinkhas J, \& Sperling O. (1982) Abnormality in renal urate handling in the syndrome of inappropriate secretion of antidiuretic hormone. Isr J Med,18,pp.711-713.

Welt LG, Seldin DW, Nelson WP, German WJ, \& Peters JP. (1952) Role of the central nervous system in metabolism of electrolytes and water. Arch Int Med,90,pp.355-378)

Wijdicks EF, Ropper AH, Hunnicutt EJ, Richardson GS, \& Nathanson JA. (1991) Atrial natriuretic factor and salt wasting after aneurysmal subarachnoid hemorrhage. Stroke,22(12),pp.1519-1524.

Wijdicks EF, Schievink WI,\& Burnett JC Jr. (1997) Natriuretic peptide system and endothelin in aneurysmal subarachnoid hemorrhage. J Neurosurg, 87(2),pp.275-80 (ANP)

Wijdicks EF, Vermeulen M, Haaf JA, Hijdra A, Bakker WH, van Gijn J. (1985) Volume depletion and natriuresis in patients with a ruptured intracranial aneurysm. Ann Neurol,18,pp.211-216

Wijdicks EF, Vermeulen M, Hijdra A, \& van Gijn J. (1985) Hyponatremia and cerebral infarction in patients with ruptured intracranial aneurysm: Is fluid restriction harmful. Ann Neurol,17,PP.137-140

Yamamoto T, Moriwaki Y, Takahashi S, Tsutsumi Z, \& Hada T. (2000) Effect of losartan potassium, an angiotensin II receptor antagonist, on renal excretion of oxypurinol and purine bases. J Rheumatol, 27,pp. 2232-2236

Youmans S, \& Maesaka JK.(2011) Urine of patients with cerebral/renal salt-wasting syndrome contains a substance that inhibits reabsorptive sodium flux in LLC-PK1 cellsAbst. Annual Mtg Am Soc Nephrol, Philadelphia, PA, USA

Zerbe R, Stropes L, \& Robertson G. (1980) Vasopressin function in the syndrome of inappropriate antidiuresis. Annu Rev Med, 31,pp.315-327 


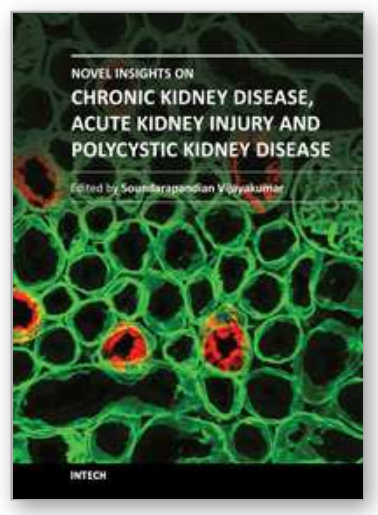

\section{Novel Insights on Chronic Kidney Disease, Acute Kidney Injury and Polycystic Kidney Disease}

Edited by Dr. Soundarapandian Vijayakumar

ISBN 978-953-51-0234-2

Hard cover, 134 pages

Publisher InTech

Published online 07, March, 2012

Published in print edition March, 2012

This book offers novel insights on topics such as congenital obstructive nephropathy, cerebral-renal salt wasting, and the role of hemoglobin variability in clinical outcomes of CKD which are not very often discussed in the literature. With comprehensive and insightful reviews by eminent clinicians and scientists in the field, this book is a valuable tool for nephrologists.

\section{How to reference}

In order to correctly reference this scholarly work, feel free to copy and paste the following:

John K. Maesaka, Louis Imbriano, Shayan Shirazian and Nobuyuki Miyawaki (2012). Complexity of Differentiating Cerebral-Renal Salt Wasting from SIADH, Emerging Importance of Determining Fractional Urate Excretion, Novel Insights on Chronic Kidney Disease, Acute Kidney Injury and Polycystic Kidney Disease, Dr. Soundarapandian Vijayakumar (Ed.), ISBN: 978-953-51-0234-2, InTech, Available from:

http://www.intechopen.com/books/novel-insights-on-chronic-kidney-disease-acute-kidney-injury-andpolycystic-kidney-disease/challenges-of-differentiating-cerebral-renal-salt-wasting-from-siadh-emergingimportance-of-determin

\section{INTECH}

open science | open minds

\section{InTech Europe}

University Campus STeP Ri

Slavka Krautzeka 83/A

51000 Rijeka, Croatia

Phone: +385 (51) 770447

Fax: +385 (51) 686166

www.intechopen.com

\section{InTech China}

Unit 405, Office Block, Hotel Equatorial Shanghai

No.65, Yan An Road (West), Shanghai, 200040, China

中国上海市延安西路65号上海国际贵都大饭店办公楼405单元

Phone: +86-21-62489820

Fax: +86-21-62489821 
(C) 2012 The Author(s). Licensee IntechOpen. This is an open access article distributed under the terms of the Creative Commons Attribution 3.0 License, which permits unrestricted use, distribution, and reproduction in any medium, provided the original work is properly cited. 